\title{
Research on Design Inheritance and Development Strategy of Feather Painting in Shenyang
} Yuchen $\mathrm{Gao}^{1, \mathrm{a}}$, Haonan $\mathrm{Ma}^{2, \mathrm{~b}^{*}}$

\author{
${ }^{I}$ Department of Design and Art, Shenyang Aerospace University, Shenyang, Liao Ning, China \\ ${ }^{2}$ Department of Design and Art, Shenyang Aerospace University, Shenyang, Liao Ning, China \\ a29312967@qq.com \\ b*191576987@qq.com
}

\begin{abstract}
Through the study of the design inheritance of Shenyang feather painting, the artistic value and cultural connotation of feather painting are systematically excavated, so as to improve the public's attention to feather painting, and make feather painting get more powerful inheritance and healthier development.Let Shenyang feather painting carry forward, at the same time to develop it into a best-selling cultural travel products, promote the economic development of Shenyang tourism industry.In this paper, literature analysis and historical analysis are used to sort out the development history of Shenyang feather painting.Secondly,the design inheritance research is carried out from the two aspects of style characteristics and theme selection.Finally, four design-based multi-level exploration development strategies of Shenyang feather painting are drawn. First, design innovation is carried out to integrate with modern design elements in terms of themes, materials and practicability. Second, through the integration of new carriers to carry out publicity, spread influence, such as public facilities;Third, consider product price range stratification, through simple but do not lose the charm of low-cost products to open the market;Fourth, cooperate with government propaganda to infiltrate feather painting culture into citizens' life from a subtle point.
\end{abstract}

Keywords: feather painting, inheritance, traditional techniques, the development strategy

\section{沈阳羽毛画的设计传承与发展策略研究}

\author{
1 沈阳航空航天大学设计艺术学院, 沈阳, 辽宁, 中国 \\ 2 沈阳航空航天大学设计艺术学院, 沈阳, 辽宁, 中国 \\ a29312967@qq.com \\ b*191576987@qq.com
}

高雨辰 $1, \mathrm{a}$ 马昊楠 $2, \mathrm{~b}^{*}$

\begin{abstract}
摘要
通过研究沈阳羽毛画的设计传承之路, 系统挖掘羽毛画的艺术价值以及文化内涵, 提高民众对羽毛画的关注度, 使羽毛画得到更有力的传承和更健康的发展。让沈阳羽毛画发扬光大，同时将其开发成畅销的文旅产品，促进 沈阳旅游产业经济发展。本文使用文献分析法与历史分析法, 首先梳理了沈阳羽毛画的发展历史; 其次横纵双 向对比，从风格特色、题材选择两方面进行设计传承研究; 最后得出四条以设计为主的沈阳羽毛画多层次的探 索性发展策略: 第一, 进行设计创新, 从题材、材料和实用性方面分别与现代设计元素融合; 第二, 通过融合 新载体的方式进行宣传、扩散影响力，如公共设施等; 第三，考虑产品价格区间分层，通过简易但不失本韵的 低价产品打开市场; 第四, 配合政府宣传, 从细微之处将羽毛画文化渗透到市民的生活中去。
\end{abstract}

关键词: 羽毛画; 传承; 传统工艺; 发展策略 


\section{1. 前言}

沈阳羽毛画是我国独创的具有深厚文化底蕴的 传统工艺美术品, 对其研究有利于弘扬民族精神, 对 现代工艺美术和设计发展具有积极意义。然而, 沈阳 羽毛画的传承正走向消亡。由于其工序复杂多样、材 料稀有多变的特性, 掌握这门手艺的人越来越少, 这 项从上个世纪延续下来的传统手工技艺不能发扬, 影 响力越来越弱。时代之魂需以文艺之光重铸, 繁荣沈 阳羽毛画符合当代公共文化百花齐放、百家争鸣的方 针, 能够让人民群众拥有更丰富、高质量的精神文化 生活。为此, 本文梳理沈阳羽毛画历史, 并与其他 地区对比概括特色, 最终得到其符合时代特征的发展 策略。

\section{2. 羽毛画概述}

羽毛画是运用各种禽鸟毛羽, 汲取国画构图技法 制成的一种工艺画类。从设计、选毛、粘贴经过 30 多 道繁杂工序, 尤其要根据正羽、线羽、毛羽的特性、 大小、粗细及色彩搭配使用。手工制作, 技术要求之 高超, 工艺之精细是国画、水粉画、油画等所不能比 拟的。作品设计新颖, 底色自然流畅, 画面典雅高贵, 色泽丰富鲜艳且永不褪色, 给人以自然天成之美感。 一帧精美的羽毛画, 少则几百元, 多则上万元。无论 是代表东方绘画艺术的中国画, 还是西方文艺复兴时 期的艺术大师们留给后人的森林及田园风光等上乘 之作, 均能通过羽毛画予以独特风格的艺术再现, 同 时, 格调清新、古色古香又不失华丽。具有很高的观 赏价值和收藏价值, 因而受到各方人士的赞誉和喜爱。 从 20 世纪 60 年代开始, 羽毛画就被指定为国家领导 人出国访问的礼品之一。

沈阳羽毛画是羽毛画中的一个地域派别, 产自历 史文化名城辽宁省沈阳市, 以内容丰富, 规格、品种 繁多, 素以典雅秀丽的独特风格著称于世。它巧妙地 运用大自然各种禽鸟的羽毛, 取其天赋的色彩和光泽, 广泛地吸收中国牙雕、锒嵌等传统艺术精华, 采用中 国画构图形式、章法与现代艺术相结合。通过因料施 艺、精心设计, 加以剪切、雕刻、嵌贴等 60 多道精 湛细致的工序而制成。表现人物、风景、动物、花鸟、 静物等内容。后又研制了西式画、装饰画、羽毛小制 品等。它高度强调作工, 突出工艺手段, 形象生动逼 真, 具有鲜明的地方特色, 是亦工亦艺, 清秀淡雅, 栩栩如生, 独具一格的传统工艺。该产品对羽毛原料 采取了“MA” 喷涂处理新工艺, 达到了彻底防止虫蛙, 在国内外取得了广泛赞誉认可。沈阳市羽毛画厂生产 的银铃牌羽毛画, 1980 年获轻工业部优质产品称号, 1984 年获国家银质奖; 1989 年获首届北京国际博览 会金奖。沈阳羽毛画 “七五” 期间出口创汇达 635 万 美元 $[1]$ 。

\section{3. 沈阳羽毛画的发展历程梳理}

早在春秋战国时期出现了羽毛贴画，只是一种简 单的表现形式, 且杂以彩绘; 到了汉代的羽毛贴画绢, 做工比较细致, 色彩比较鲜明, 有了一定的布局与格 调。在长沙发掘的西汉马王堆墓中, 就已有羽毛装饰 品并得以印证; 而到了唐代的立女屏风, 才使其成为 一个工艺美术表现形式的独立品种。直至清代点翠松 竹座屏的出现, 羽毛画的表现形式, 内容以及粘贴技 艺都达到了至善尽美的程度。至今，在沈阳故宫关睢 宫内还悬挂着当年皇太极送给爱妃海兰珠的两幅羽 毛画, 虽历经沧桑数百年, 仍然不褪色, 不变质, 是 宫廷御用的珍贵工艺品。但其制作工艺长期失传。解 放后, 我国的美术工艺大师、老艺人携手在传统画的 基础, 创造出现代的羽毛画制作工艺, 使羽毛画艺术 品又了长足的发展。现代羽毛画在沈阳至今, 走过了 一条从兴起、兴盛, 再到衰退, 乃至现在的濒危之路。

\section{1. 沈阳羽毛画的兴起}

沈阳羽毛画兴起于 20 世纪 60 年代。准确的说, 羽毛画在我国的现代化复苏是从 1958 年的《喜鹊登 梅》开始的 [2]。见图 1、2。《喜鹊登梅》由沈阳市 工艺美术公司出品, 作画内容为我国传统吉祥图案之 一的喜鹊登梅, 寓意吉祥喜庆、好运到来。画中花叶 飞鸟皆为羽毛所制, 尤其以羽毛作鸟, 浑然天成; 加 之艺术家高超技艺裁贴, 使梅花喜鹊跃然纸上、栩栩 如生。画面整体构图疏密得当, 给人以清新活泼之感。 虽然较之后期成熟作品, 《喜鹊登梅》的图样和构思 都较为简单, 但作为我国真正意义上的第一幅现代羽 毛画, 仍是做工精致、具有收藏价值的工艺品佳作。

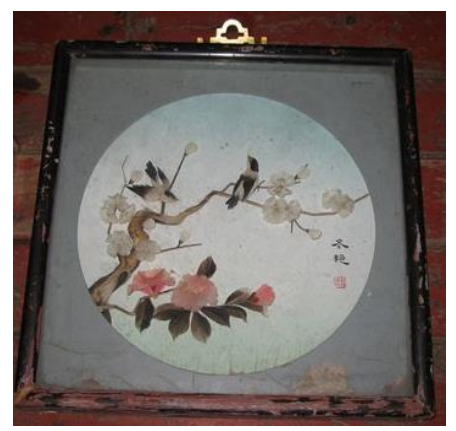

图 1 《喜鹊登梅》, 沈阳市工艺美术公司, 1958 年

以此为引, 1962 年后, 更多种类的沈阳羽毛画 开始批量生产。一经试销, 广受好评, 不仅得到美术 界专家的赞赏和众多消费者的欢迎, 更被当时中央人 民广播电台和《辽宁日报》相继宣传报道。由此, 羽 毛画在国内开创出属于自己的一方工艺品新天地。

\section{2. 沈阳羽毛画的兴盛}

沈阳羽毛画的兴盛时期为 20 世纪 60-80 年代。 各类羽毛工艺品层出不穷, 花样翻新; 各地羽毛画流 派也纷纷涌现, 在风格题材上也都特征迥异。羽毛工 
艺产业呈现出百家争鸣的态势。沈阳市羽毛画厂作为 国内最早的羽毛工厂, 不仅工人规模从原来的几十壮 大至数百人，更首当其冲，不仅创立出独树一帜的传 统宫廷与现代派相结合的羽毛画艺术品风格上也集 百家之长, 清秀淡雅、格调新颖。产品畅销海内外, 一年创汇 1000 余万美元, 是中外客商的带货首选。 70 年代末期,在题材上,从花鸟鱼虫,发展到人物、动物、 风景等。见图 2、3。

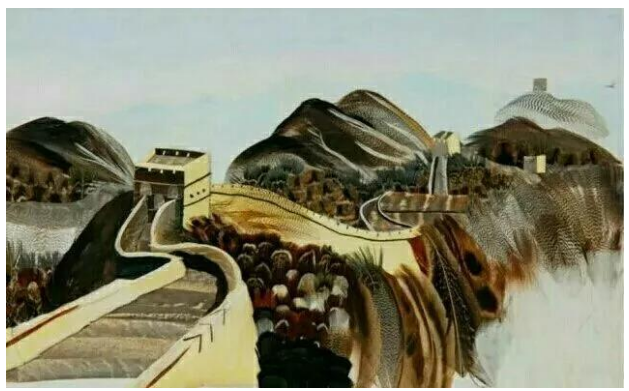

图 2 风景羽毛画

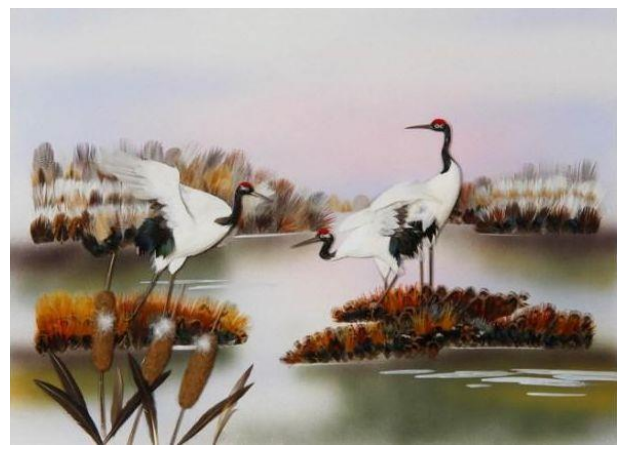

图 3 花鸟羽毛画

《陈涉起义》是由沈阳市羽毛工艺厂创始人之一 唐东全大师设计, 也是沈阳市羽毛工艺厂目前珍藏年 代最为久远的一幅羽毛画，是名副其实的镇厂之宝。 画中的人物神态各异, 服装头饰为数种羽毛制成, 纹 理细致, 生动逼真, 再现了一场恢宏大气的起义运动。 见图 4。

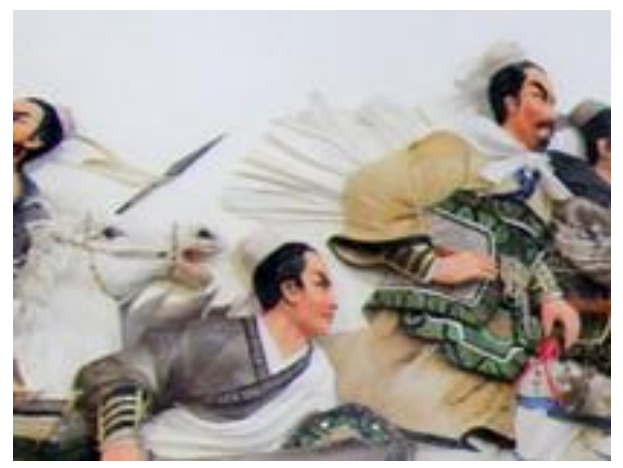

图 4《陈涉起义》局部, 沈阳市羽毛工艺厂, 唐东全, 1972

80 年代台湾电视节目主持人凌峰制作《八千里
路云和月》时拍摄的沈阳羽毛画《战吕布》, 描绘的 是我国古典名著《三国演义》中的一个精彩桥段“三 英战吕布”。见图 5。画中吕布身着白银铠甲, 腰系兽 头腰带, 黄金头盔上领羽飘然欲动; 身后披风如同风 凰的翅膀一般卷起, 雕花斧矛泓若秋水。人物或怒或 勇的神态动作尽致淋漓, 几人骑着精壮的战马在凛风 中激斗之声犹若在耳。

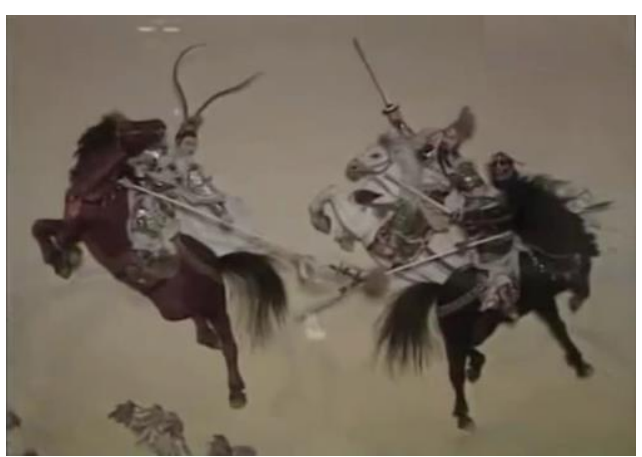

图 5 《战吕布》局部

除了传统中式题材, 海外市场的繁荣也带动了沈 阳羽毛画设计的新思路。1981 年, 在传统羽毛画的 基础上，沈阳市羽毛工艺厂根据西方民族习惯研制开 发了西画式羽毛画和装饰羽毛画。西画式羽毛画是以 北美，南美和欧洲的动、植物为主要题材,配之西方 的典型风景加以烘托, 设计方法采用交点透视法,对 要表现的景物进行写实, 远近景层次分明, 产生了意 境深远的艺术效果。见图 6 。

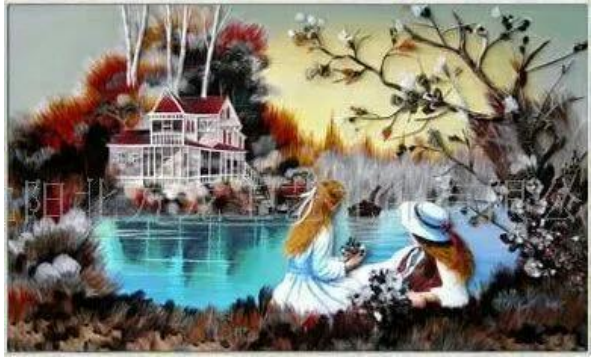

图 6 宛若油画的西式写实羽毛画

\section{3. 沈阳羽毛画的衰落}

20 世纪 90 年代, 沈阳羽毛画开始了它的衰退之 路。羽毛画精细的传统手工特性注定其生产效率低下, 不能适应现代工业化社会和高速运转的市场经济。加 之羽毛画本身易损坏、难运输的特点, 使其渐渐被批 量化的新式工艺品和成本低廉的印刷画冲击而下。同 时, 羽毛画的设计也没能跟上改革开放后人们拓宽的 眼界和日趋西化的审美品味。以师徒传授流传下来的 技艺总是多了几分程式化，少了几分风格上的创新。 因此, 名噪一时的沈阳羽毛化开始被时代洪流抛却, 逐渐走向衰退。 


\section{4. 沈阳羽毛画的濒危}

1998 年国际金融危机，2003 年非典、2004 年禽 流感, 使羽毛画内忧外患。羽毛画作为精美的民间工 艺美术, 技术复杂, 成本高昂, 走出口国际的高端销 售路线, 国外市场是主要的销售途径。随着 1997 到 1998 年的亚洲金融危机余波蔓延到全球, 羽毛画的 外销之路举步维艰。曾经的沈阳羽毛画在最辉煌的 80 年代远销美国西欧等二十多个发达地区, 年产值 一千多万美元。但随着国际金融危机带来的全球性经 济萎缩, 加之羽毛画不易保存等局限性, 各地羽毛画 的规模和产值迅速萎缩, 羽毛画厂接连倒闭, 沈阳市 羽毛画厂也仅剩几名工人艰难维持。祸不单行的是, 2003 年的“非典”和紧接而来的禽流感, 把羽毛画推向 了濒临灭绝的境地 ${ }^{[3]}$ 。

\section{4. 探析设计传承: 风格特色与题材选择}

\section{1. 沈阳羽毛画的风格特色}

沈阳羽毛画自开创以来的整体风格就保持着色 彩浓郁、雄浑硬朗, 气势磅礴, 宛若油画, 几十年来 一直得以传承。沈阳羽毛画设计选题上按时间顺序大 致为从 60 年代初刚刚兴起时选择较多的花鸟鱼虫, 技法以平贴的纱祄、卷轴、壁挂、册页为主; 后逐渐 到加入描绘山水风景, 此类主题画作以浮雕的挂屏、 座屏、大型折页屏、案头立屏居多; 再到人物故事的 主题, 这时立体羽毛画的制作工艺已相当完善了。总 体上选题和应用的工艺都遵循着由简单到复杂的规 律, 体现了沈阳羽毛工艺几十年来由探索到成熟的历 史过程。见图 7。

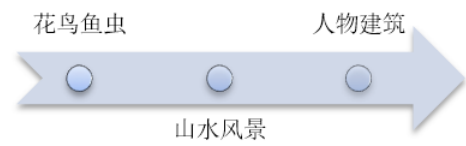

图 7 题材时间轴

沈阳羽毛画题材广泛, 内容丰富, 形式多样, 其 中的古典人物画和花鸟画尤为巧夺天工, 别具一格, 富有浓郁的民族特色。例如取材于我国古典名著《红 楼梦》中的“宝黛含情谈西厢”、《三国演义》中的“貂 婵拜月”、《西厢记》中的“崔莺月下听琴”, 以及取材 于神话传说和历史故事中的“天女散花”、“昭君出塞” 等等, 都惟妙惟肖, 驰名中外。以花鸟为题材的羽毛 画更是姹紫嫣红、绚丽多彩。例如富丽堂皇的牡丹、 凌寒斗雪的红梅、争芳夺艳的桃李、傲雪斗霜的兰竹 等, 再配以孔雀开屏、黄婯对话、鹗莺戏水、雄鹰展 翅、白鹤冲霄等景物, 令人赏心悦目, 心旷神怡。见 图 8。

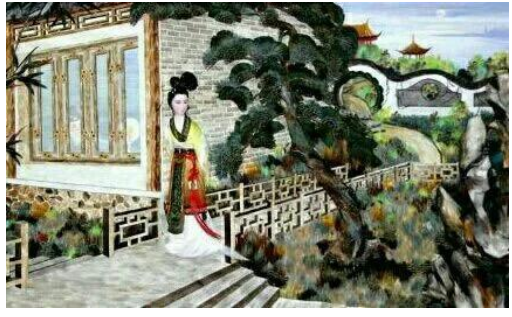

图 8 《崔苞月下听琴》

\section{2. 与其他地区羽毛画的对比}

\section{2.1 济南羽毛画}

济南羽毛画产于济南工艺美术厂, 色彩鲜艳协调、 造型生动逼真、布局合理新颖。济南羽毛画中的山水 画, 把中国画和水彩画溶为一体, 水墨淡彩, 独成风 格, 如《泰山》、《祖国新貌》等就是这种拼贴的代表 作。立体羽毛画如《电鸣鸟》, 由于质感和立体感很 强, 故形象逼真, 振翅欲飞。半立体浮雕羽毛画, 多 是装饰类的艺术作品, 其工艺方法是: 先用纸做好胎 型, 再用羽毛拼贴修饰, 制品形象逼真, 富有质感。 这类羽毛画, 《虎》是最著名的作品。它是用猫头鹰 的羽毛塑粘而成的, 在广交会上倍受外国客商欢迎, 被誉为“泉城老虎”。见图 9。

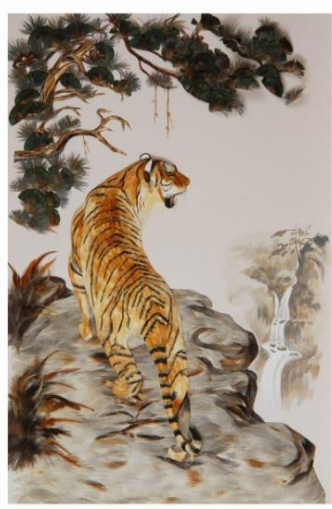

图 9 《虎啸山林》

\subsection{2 宝庆羽毛画}

宝庆羽毛画善于利用各种羽毛的天然色泽、纹彩、 亮度和质感, 色彩上强调自然本色, 给人以自然天成 之美感, 题材以山水风光、花鸟、人物为主, 具有内 容丰富、题材广泛、形式多样、造型生动、色彩鲜艳, 做工精细等艺术特点。它是在城市文人和有闲阶层中 产生的一种民间美术，其题材、内容、艺术形式表现 方法都是为了适应城市有闲阶层、文人雅士、达官贵 人的需求而产生的, 集实用、观赏和收藏价值于一身, 具有浓郁的文人气息和地方特色。

宝庆羽毛画主要有卷轴、纱祄、壁挂等品种。卷 轴羽毛画主要汲取中国水墨画的艺术形式，以绫绢装 
裱, 以供欣赏; 纱祄羽毛画吸取湘绣双面异色绣的形 式, 可正反两面欣赏; 羽毛壁挂借鉴艺术挂毯的形式, 用羽毛层层叠贴而成, 特別适合表现山水风光。以花 鸟为题材的羽毛画更是姹紫嫣红, 绚丽多彩, 大型山 水挂屏《小鸟天堂》是宝庆羽毛画的代表作。见图 10 。

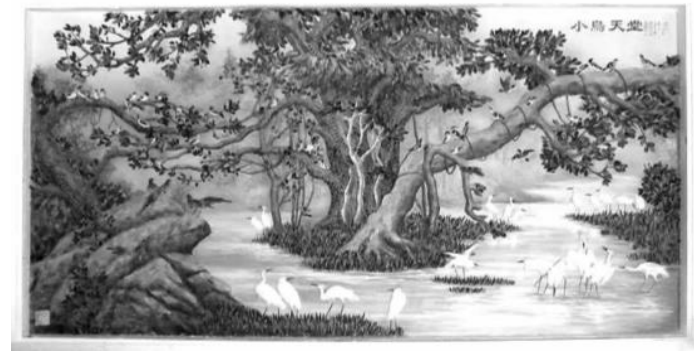

图 10 《小鸟天堂》

总结得到沈阳、济南和宝庆三地羽毛画流派风格 对比表格，见表 1 。

表 1 各流派羽毛画风格对比

\begin{tabular}{|c|c|}
\hline 流派 & 风格 \\
\hline 沈阳羽毛画 & 鲜艳明快 \\
\hline 济南羽毛画 & 清秀淡雅 \\
\hline 宝庆羽毛画 & 自然天成 \\
\hline
\end{tabular}

\section{5. 发展策略}

以沈阳羽毛画之工艺卓绝、俏丽多姿, 本应足以 使其流行于任何时代地域。但由于设计经营不善等原 因, 羽毛画并未在舞台占据应有的一席之地。笔者认 为在设计上跟随时代潮流、不断创新, 是工艺品在当 今社会的立足根本。从提升其自身艺术价值角度入手 研究, 才能吸引文化受众、使传统工艺后继有人。通 过调查分析, 笔者兼顾内外影响, 从设计元素、载体、 价格与宣传几个角度归纳出以下四种沈阳羽毛画的 再创新发展策略。

\section{1. 设计创新，与现代设计元素相结合}

第一, 在题材上, 强化地方特色, 展现鲜明个性。 让作品选题具有地方特色, 不一定要选取传统的文化 符号或古典故事, 也可以描绘近现代的城市发展足 迹，用羽毛展现沈阳地铁的高速建设等。

第二，在材料上，考虑与其他新材料、新工艺搭 配。技术的含量与进步能够有效的提升画作艺术价值,
如给羽毛上色时运用可变色染料, 可以使作品部分颜 色根据温度湿度不同而有所变化, 增加趣味性或打造 渐变色彩。也可在羽毛中加入闪粉、金属丝, 使羽毛 画具有更美观更多层次的视觉效果。持续性的技术与 材料创新, 是特色技艺的生命力之源。

第三, 从增强其实用性考虑: 丰富羽毛产品种类, 如永不褪色枯萎的羽毛花束、艳丽柔软的羽毛座垫等。 也可以考虑与服装设计专业结合, 把羽毛画元素加入 到多种多样的服装饰品中去，如领结、背包等等。

需要注意的是, 在创新设计的同时也要注重保留 和发扬原本的沈阳羽毛画地方特色, 尽量选取相得益 彰的时尚元素进行组合, 不能盲目添加新元素而降低 了羽毛画本身的文化韵味。

\section{2. 融合新载体}

可以通过融合新载体的方式进行宣传、扩散影响 力, 如与公共设施, 甚至与其他传统工艺联合进行创 作设计。如夏月曼提议将非遗堆漆画融入到芜湖轨道 交通文化墙设计中, 打造出具有堆漆画特色的轨道交 通站点 ${ }^{[4]}$ 。以沈阳轨道交通为例, 经笔者观察, 沈阳 地铁等大型交通轨道周边文化墙体仍有大量空白, 用 传统工艺美术作品填充既能美化城市环境, 又能通过 这一强流量载体时刻传播特色文化，增强市民文化自 信, 不失为一种好选择。另有一种选择是与本土知名 度较高的故宫文化、满清文化进行联名活动, 比如融 入被誉为“中国起源地文化项目”的盛京满绣, 创作与 满绣经典龙纹绣相对应的“凤羽图”; 协力打造同时具 备彼此特征元素的文化产品, 既能拓宽受众和市场, 也给双方的设计血脉中都增添新的活力。

\section{3. 价格区间分层}

从营销方式考虑, 沈阳羽毛画不应仅仅着眼于价 格高昂、大众难以企及的高端市场, 也可以通过设计 出简易小巧的低成本种类扩大受众市场，提升国民度。 如: 在庆典集市和线上售卖材料和教程一体的 DIY 包作为老少咸宜的时尚礼品, 既能带动收入经济增长, 又能为顾客和收礼人普及羽毛画的制作方法和理念, 无形中铺开了吸引工艺传承人的良性途径。

\section{4. 加强宣传}

大众对商品的认知会影响到购买意愿 ${ }^{[5]}$ ，因此传 统工艺的复兴也离不开政府的宣传配合。如沈阳近年 建立的满绣文化产品旅游生产基地, 通过生产基地平 台、结合教学发展技艺传承人，进行民族文化的传承 和传播, 促进了艺术创新和产业升级。仿照此例, 沈 阳市政府可以通过打造羽毛画文化园特色展区、加强 复兴传统艺术热点教育、在各类广告宣传片中进行文 化软植入等方式进行对沈阳羽毛画的产业扶持; 令羽 毛画有朝一日重为沈阳骄傲的特色礼品, 不使优美的 传统工艺因无人知晓埋没于工业化尘土之中。 


\section{6. 结论}

民间艺术在早期只是人们生活的装饰, 或者只是 为了迎合节庆或宗教的需要而形成的一种技艺。只是 经过了岁月的洗炼之后, 它流传了下来, 而在机器商 品的时代里, 对思古幽情发挥了稀有而独特的价值。 人们因此而赋予它“艺术”的地位。而当民间的艺术越 来越淡薄时, 它却越来越艺术。因此, 保护民间工艺 就是保护历史, 复兴传统工艺就是复兴辉煌。沈阳羽 毛画作为曾经辉煌灿烂的民间工艺, 已因时代的抛却 蒙尘许久。每个人都是故乡的子民, 作为设计研究者 的我们, 在未来有义务进一步了解故乡历史, 发掘问 题、探求策略, 助地方民族技艺焕发应有的光彩。

\section{REFERENCES}

[1] Shenyang municipal district office. (1988) Shenyang agricultural products. Liaoning Science and Technology Publishing, Shenyang.

[2] Centre for strategic research on the development of light industry. (1991) Yearbook of China's light industry. China Light Industry Publishing , Shenyang.

[3] Chen C., Gan L., Peng Y. (2013) A brief analysis on the protection, inheritance and development of baoqing feather painting in the new era. Beauty and times (China), 12:67-68.

[4] Xia Y. (2019) Research on the fusion of "intangible cultural heritage" culture and rail transit design -- a case study of pile painting. Journal of Beijing institute of printing and technology, 27(09):51-53.

[5] Lv N., Zhang J. (2019) Research on the Impact of Online Travel Bundled Sales Price Framework on Tourists' Purchase Intentions_- The Mediation Effect of Perceived Transaction Value and the Moderating Effect of Brand Perception. Travel Guide, 3(04): 30-49. 